\title{
The Think\&EatGreen@School Small Grants Initiative: How the Distribution of Resources Supported the Project's Community of Learners and Contributed to Community Engaged Scholarship
}

\author{
Elena Orrego, Matthew Kemshaw, Nicole Read, Alejandro Rojas
}

\begin{abstract}
This paper describes how a Small Grants initiative evolved to support the aims of a large, multi-sector community-university research project. It explores how the giving of small amounts of project funding to community groups enabled a deepening of community engaged scholarship across a large community-university research alliance. We present the Think\&EatGreen@School Small Grants initiative as a case study on how the distribution of small amounts of funding can encourage the role of community voices in research, create opportunities for resource and knowledge sharing, generate rich information and valuable data, support and contribute to networks of support and resource sharing, and articulate the interests of a broad diversity of stakeholders.
\end{abstract}

KEYWORDS community engaged scholarship, trust, grants

This paper describes how a Small Grants Initiative emerged as an important part of the process of ensuring community participation and engagement in the Think\&EatGreen@ School research project (TEGS). Born of a collaboration between the Vancouver Board of Education, the University of British Columbia, and dozens of community partners, TEGS worked from 2010 to 2015 to create healthy, sustainable school food systems in Vancouver. The project sought to enable students, teachers, and policy makers to influence how their food is produced and where it comes from, and to create knowledge that might support the deeper integration of healthy, sustainable food in Vancouver Schools. TEGS began with a commitment to working collaboratively with a diverse and representative community of learners, and evolved iteratively over the years to support and incorporate a wide network of stakeholders in the research goals. Throughout, this paper touches on aspects of our approach to Community Engaged Scholarship and shows how the Think\&EatGreen@School Small Grants Initiative became an important tool to help frame common goals while creating a synergistic network of community stakeholders to work towards them.

The Small Grants Initiative was created by the TEGS project as a way to support the engagement of school communities in school-based healthy and sustainable food system projects in Vancouver public schools. The distribution of small grants to a diversity of 
community stakeholders enabled trust and teamwork to grow within our networks, while deepening communication between university and community team members. The Initiative not only increased the legitimacy of our work in the eyes of the community of practitioners we sought to reach, but also gave community stakeholders a voice in crafting our research objectives and bringing them to life. The Small Grant Initiative was also valuable for generating useful data to support our research project's development and findings.

TEGS' Small Grant Initiative was established in the second year of the TEGS research project. The primary outcomes we hoped to achieve were as follows:

- Listening to key stakeholders: schools, teachers and NGO community partners, in order to better understand what schools needed. We also wanted to specifically identify which schools and teachers had an interest in carrying out Think\&EatGreen@ School initiatives;

- Increasing our contacts within the Vancouver School Board;

- Understanding better the goals and objectives of individual school communities;

- Finding educators, students, parents, and other school community members who were genuinely interested in school food system change;

- Recording and mapping the work that schools in Vancouver were doing to implement healthy, sustainable school food systems;

- Convening a synergistic network of stakeholders working towards overarching goals for Vancouver's school food system;

- Strengthening connections with individual schools in order to connect students from UBC to action-research opportunities that could address the real needs of the community while working as part of our community-engaged scholarship approach.

These objectives were defined by the TEGS core team and developed through an iterative and oral process. They were held and coordinated by our lead author over the 4 years of the Think\&EatGreen@School Small Grants initiative, from 2011-2014.

\section{Emergence of the Small Grants Initiative}

The core research team's initial project description included a commitment by TEGS to focus on "Projects of Community Impact." At that point a specific mechanism to elicit the voice of individual school communities was not yet developed. We agreed within our team of UBC researchers and community partners ${ }^{1}$ that the problems, objectives, and outcomes must be jointly defined. However, at this point in the process, some of the people most involved in school food systems, that is, teachers, K-12 students, and parents (with the exception of only three school teachers) were not initially a part of this consultation process or the TEGS core research team, although all community partners were involved in the preparation of the original research grant application submitted to the Social Sciences and Humanities Research Council of Canada. A small proportion of the original research budget had been set aside for

\footnotetext{
${ }^{1}$ Including non-profit organizations, public health institutions, members of the Vancouver Board of Education, and other university-based researchers.
} 
"Community Engagement," with the hope of finding equitable ways to meaningfully engage a broad spectrum of people from individual school communities within our community of learners. We acknowledge that in the beginning we did not fully know the concrete mechanism(s) that we would use to work in true partnership with school communities, though we assumed these would emerge. During the project's first year, the idea of the Small Grants program was born. Our community engagement budget would become the seed funding we needed to start the Small Grants initiative.

By the end of our first year, we were fully committed to the practice of CommunityEngaged Scholarship (CES) and felt a need to "walk the talk," and thereby create relationships of reciprocity and trust with individuals and schools, and within our existing alliance. Our core team realized that the "[d]irect involvement of people affected by the problem under study facilitates a more accurate and authentic analysis of their social reality. By directly involving those affected and those serving the affected, experiential knowledge is brought to the research process" (Balcazar, Keys, Kaplan, \& Suarez-Balcazar, 1999, p.92; See also Harper \& Carver, 1999; Selener, 1997). The TEGS research team assumed that by including teachers and others involved at the individual school level, our larger community of learners would be able to meaningfully connect with, and learn from, individual school experiences, thereby significantly improving our capacity to achieve socially relevant outcomes (Hemlin and Rasmussen 2006; de Jong et al. 2011). As Carew \& Wickson (2010, p.1147) articulate, we wanted to integrate "potentially disparate knowledges with a view to creating useable knowledge. That is, knowledge that can be applied in a given problem context and has some prospect of producing desired change in that context." The Small Grants initiative became one important way to invite individual school communities into the discussion as valued participants in our research team.

\section{Distributing Small Grants}

Starting in TEGS' second year, the Small Grants initiative was created as a pilot effort to increase participation and action from teachers, students, administrators, and parents. Over four years of administering funding through the Small Grants initiative, TEGS provided $\$ 110,000$ to 57 public schools within the Vancouver School Board (VSB). School-based teams developed concrete proposals, using our grant application form, in response to TEGS' call for the submission of proposals for funding. Each year, TEGS allocated a set amount to the Small Grants initiative, and this money was distributed amongst all applicant schools. We did not turn any school team down, so long as their application was complete and submitted within the application period. Resources were distributed amongst all applicant schools based on the established application criteria, with more funds going to projects that demonstrated higher potential for achieving significant action outcomes.

The amount that we were able to give schools increased over the years, as we received contributions from the Vancouver Retired Teachers' Association and the Vancouver School Board. We distributed grants from $\$ 200-\$ 2,000$ to individual school teams. To ensure the transparency of the process of allocating the project's resources, a process of application to 
the Small Grants initiative was created and a decision-making committee was formed, with representatives from the UBC team, the VSB, Vancouver Coastal Health, and the project's notfor-profit community partners (see Figure 1 for application criteria). The committee evaluated school-based projects and provided feedback to help support each school project in clearly defining and achieving its objectives. Flexible guidelines were provided by the leadership of the project, so teams could develop action plans tailored to specific school needs, while fitting within a framework of key goals identified by TEGS' core research team.

Figure 1: Small Grant Application Criteria

\section{Application Criteria for 2011-2013 Small Grants Initiative}

\section{Criteria for becoming a Think\&EatGreen School}

Priority will be given to schools that can demonstrate (as many as possible of) the following criteria:

o Involve a working team of $\mathbf{3}$ or more members committed to strengthening the connections within the food system at their school. This team may include teachers, administration, support staff, food service staff, maintenance staff, students, parents, or other community members. At least one team member must be a teacher, administrator or other school staff member.

o Demonstrate a commitment to initiatives that make connections between different aspects of the school food system and provide opportunities for student learning and activities such as growing, preparing and sharing food and managing food waste.

o Involve partnerships with community-based organizations and/or other schools.

\section{Application Criteria for 2014-2015 Small Grants Initiative}

\section{Criteria for becoming a Think\&EatGreen School}

Priority will be given to schools that can demonstrate (as many as possible of) the following criteria. Where applications are of equivalent merit -- according to the listed criteria -- preference will be given to applications that include a partnership with another elementary or secondary school.

o Partnerships between at least two schools with a joint application for Food System activities at both the schools.

o Partnerships between a community organization and the applicant school(s).

o Concrete action projects for improving aspects of the Food System at the school.

o Creation of lesson plans around Food Systems that can be shared with other schools and interested parties.

o Involve a working team of $\mathbf{3}$ or more members in each school who are committed to work collaboratively for healthy and sustainable food systems at their school. This team may include teachers, administration, support staff, food service staff, maintenance staff, students, parents, or other community members. At least one team member must be a teacher, administrator or other school staff member. 


\section{A Rich Source of Data}

Individual applications submitted by school teams provided insight into the unique needs and interests of food systems projects in Vancouver schools. For example, each year, schools were asked to identify and explain what was in place in their school communities, with space for specific details about school gardens, school composting systems, school cooking programs, curriculum integration with whole food cycles, lunchrooms and connections to local farms, school lunch/meal programs, and any other relevant school activities that were applicable to 'TEGS' research objectives. In addition, schools were also asked to identify members of their school teams; describe a work plan that identified objectives, specific actions, timelines, and associated budgets; answer questions about how they would evaluate the success of their participation in the project; and describe ways in which their school would integrate academic curricula with whole food system experiences.

Beginning in the 2012/13 school year, schools that received Small Grants were also asked to complete a voluntary self-assessment survey shortly after receiving their grant. This tool was developed by the TEGS research team to monitor, alongside other monitoring tools (see also Black et al., 2015; Ahmadi et al., 2014), the evolution of school food systems and food education in the schools that received Small Grants. The self-assessments provided information about the goals, barriers, and activities that individual schools were experiencing in their work developing school food systems change, and were collected during an in-person meeting near the beginning of each school year.

Along with completing a self-assessment, each Small Grant recipient school in the middle two years of our project was also required to submit photos and text to create a unique poster report at the end of the school year. The poster reports were based on a template format created by the TEGS core team. We have digital versions of posters from all four years of the initiative, some of which are available for viewing at www.thinkeatgreen.ca. These posters helped the TEGS community of learners to determine if schools were able to carry out their objectives as set in the application, and what barriers they faced in trying to reach these objectives. Posters were displayed during a final end of year meeting of all Small Grant schools, and then given to each school for them to display in their school. This end of season meeting of all the TEGS Small Grant recipient teams became a useful forum for community building, sharing of experiences, and mutual support.

For the years 2012, 2013, and 2014, we also compiled many notes and reports on many of the Small Grant schools. Internal reports and observations were written and discussed by TEGS research assistants, who were working directly with school teams to support their project objectives. In the year 2013, polished reports were formatted as short stories in a journalistic style (700 words approx.) and given to each of the schools to support their project development. 
Table 2: Data collected and resources distributed for the duration of the TEGS Small Grants (SG) initiative from 2011-2015.

\begin{tabular}{|l|l|l|l|l|}
\hline & $\mathbf{2 0 1 1 - 2 0 1 2}$ & $\mathbf{2 0 1 2 - 2 0 1 3}$ & $\mathbf{2 0 1 3 - 2 0 1 4}$ & $\mathbf{2 0 1 4 - 2 0 1 5}$ \\
\hline \# of Schools Involved & 14 & 17 & 33 & 38 \\
\hline \# of Applications & 14 & 17 & 33 & $26^{2}$ \\
\hline Poster Reports & - & 17 & 33 & $-{ }^{3}$ \\
\hline Short Stories & - & - & $33^{4}$ & - \\
\hline Self Assessments & -5 & 16 & 31 & - \\
\hline Funds Distributed & $\$ 20,000$ & $\$ 21,000$ & $\$ 35,000$ & $\$ 43,000$ \\
\hline
\end{tabular}

\section{Trust, Engagement, and Celebration}

Throughout, TEGS has sought to create relationships of mutual trust. A key goal of the Small Grants initiative was to incorporate a diverse range of stakeholders as valued investigators in our community of learners, helping to establish the research process as trustworthy, fair, and valuable in the eyes of those who stand to benefit from and/or use the research (Cash et al., 2002). As Belcher et al. (2016) explain, "legitimate transdisciplinary research 'considers appropriate values, concerns, and perspectives of different actors' (Cash et al., 2002) and incorporates these perspectives into the research process through collaboration and mutual learning." The Small Grants provided a mechanism to involve a diversity of stakeholders' perspectives in the TEGS team and provided a useful forum for exchange and sharing.

One of the most unique aspects of TEGS' Small Grants initiative has been its ability to give schools autonomy in deciding their own priorities, challenges, capacities, and needs when applying for funding, while at the same time providing overarching criteria that Small Grant school-based teams agree to abide by, which reflect the goals of TEGS (See Figure 1). The decision to give schools autonomy in deciding their own project goals and activities helped address potentially disabling power dynamics. In community/university research, inequitable distribution of power and control is a frequently mentioned challenge (Israel et al., 1998). TEGS' core research team was concerned about the distribution of power, especially at the start of the process, as we were still unsure how the concrete mechanism to work in true partnership with the school communities would evolve. Still we felt that "[w]hile challenges faced by communities may be initially recognized by academia, they can be addressed in a way that validates community partners as valid actors in producing knowledge and being part of the solution process" (Korzun et al., 2014, p.107). The Small Grants initiative was a key way to

\footnotetext{
2 2014-2015 was the first year that the Small Grants team put an emphasis on forming partnerships between schools. That is why there are more schools than grant applications for the 2014-2015 year.

${ }^{3}$ As the project ended before the end of the school year in 2015, graduate research assistants did not visit to collect data for reports.

${ }^{4}$ Short stories were only written for the 2013-2014 schools.

${ }^{5}$ Self-assessments started in 2012.
} 
support and validate community partners in these processes.

To establish trust and mutual respect in a research community, everyone needs time to get to know the contexts and perspectives of the different stakeholders (Suarez-Balcazar et al., 2004). Community Engaged Scholarship requires stakeholders to hold a positive attitude about the collaborative partnership (Foster-Fishman, Berkowitz, Lounsbury, Jacobson \& Allen, 2001; Mattessich \& Monsey, 1992; Nyden et al., 1997). TEGS regularly convened recipients of Small Grants schools and the larger community-university research alliance in face-to-face meetings, in order to help facilitate strong, positive, and collaborative partnerships between hundreds of involved stakeholders. An example of such collaboration was seen in VanTech Secondary's 2011 poster, where they said that the momentum and energy of "the Small Grant from TEGS has facilitated Van'Tech teachers pursuing urban agriculture projects, resulting in a partnership where [Fresh Roots Urban Farm Society] is so excited and honored to be growing the first Schoolyard Market Garden in Canada with the VanTech school community."

Our team convened the recipients of Small Grants Schools twice each year as soon as grants were awarded (this is when self-assessments were completed), and again to celebrate all of the projects undertaken by school teams (when we presented school posters). For four years we also hosted an annual two to three day professional development Institute (Rojas et al., publication pending), which created further opportunities for communication and sharing. These gatherings helped develop relationships of trust, wherein common goals and shared visions were articulated. School stakeholders participated in an environment of openmindedness, which acknowledged that there are many 'ways of knowing', and sought to create a shared feeling of reciprocity.

Regularly present at all of these meeting, we as authors were witness to a growing feeling of conviviality and trust. In the third and fourth year of the Small Grants project, we saw that those who came to gatherings shared stories, sought advice, traded contact information, and embraced in a spirit of community solidarity where hugs and warm greetings were ubiquitous. At our final Small Grants meeting in 2015, more than 40 people stayed beyond the meeting's official close at 6:00 pm, even though the vast majority had started the school day at around 8:00 am. At our final public event, the 2015 Think\&EatGreen@School Institute, our community voluntarily lingered late on a Saturday afternoon, well after both our Principal Investigator and our Project Manager had delivered their final closing speeches. Instead of quietly dispersing, the group insisted on gathering in a large circle of over 50 people in a silent sharing of positive intention, as we each passed a squeeze from one held hand to the next. During this final event it was commonly agreed by the many school community members present that the TEGS Project had played a vital role in connecting and communicating a shared vision of healthy school food systems in Vancouver.

\section{Looking at the Impact of Small Grants through Multiple Lenses}

In this section we tell the story of the Small Grants initiative from three different perspectives: an elementary school, a community-based NGO partner, and a university-based researcher. Through these perspectives, we see in turn how the Small Grants initiative has supported trust 
and teamwork, self-sufficiency, an equal distribution of power, and the generation of rich data.

\section{Queen Elizabeth: Trust and Teamwork}

At Queen Elizabeth Elementary (QE), the Small Grants initiative played an important role in developing strong relationships between school staff, community organizers, and universitybased researchers. The school's perspective shows how the Small Grants' process promoted reciprocal relationships based on trust and teamwork, a critical pre-requisite to conducting effective Community-Engaged Scholarship (Suarez-Balcarez et al, 2005). Among the more than 40 schools involved in the Think\&EatGreen@School network, QE stands out as a telling example of the facilitative power of Small Grants, alongside the other TEGS initiatives, in supporting the Community-Engaged Scholarship approach. Over their five years of participation in our community of learners, QE's school food initiatives significantly evolved from the seed of an idea planted by one very motivated teacher to a flourishing food garden capable of becoming a transformative feature within the school's food culture.

A key first step in QE's journey towards a culture of integrated food cycle learning was the connection made between the school's food system champion, teacher Natasha Tousaw, and Catriona Gordon, the School Garden Coordinator for the local non-profit, and TEGS Community Partner, Society Promoting Environmental Conservation (SPEC). This connection formed early in the school's journey towards wholly integrated school food systems (just months before TEGS began). The relationship would become a cornerstone and key first step in building a collaborative culture around food that was based on teamwork and mutual trust. As Natasha explains, "I could not have done this without SPEC. I could've done a little bit, but without Catriona's connections to others and to other schools... it would have been really slow going." Natasha explains that at Queen Elizabeth, it wasn't teachers who first got on board as "key investors," but that it was instead "Catriona and [her] one key parent [who] have been really key in that." She then adds that "a team is important, critical. You can't do anything on your own." Yet the reality of non-profit funding loomed heavily over Natasha and Catriona's relationship:

Every year we wondered if she was going to be able to come back or not. And that was one of the big fears with expanding the garden beyond myself and my colleague who was right next door to me...I knew that I would be capable of teaching the curriculum and integrating it into the curriculum, and my own teaching, but I wasn't sure if anyone else could. And luckily Catriona has been able to stay on [to support that].

These comments were made in 2012, when QE's garden was still in a stage of becoming. Over the following three years, the school utilized TEGS' Small Grants Initiative to maximize the impact of this relationship. Using TEGS' funds, they substantially upgraded their garden and food efforts to a point where all classes in the school were experimenting with deeper engagement in some aspect(s) of the school food cycle. 
Through TEGS in general, and the Small Grants Initiative specifically, the school received both garden development funds and UBC student support, which enabled the teachers at QE to become meaningfully involved in the garden: "The grants have enabled us to expand our garden in such a way that we can, or we could, have every class planting something if they wanted to. To me that's huge because it's making this available to everybody. The possibility for everybody to be involved is there and it wouldn't have been without the involvement of TEGS." This support was a key physical offering that supported teachers in creating healthy school food change at QE.

Another equally important, if non-physical, aspect of TEGS' support for QE is expressed in Natasha's enthusiasm and appreciation. As a regular attendee of TEGS' Small Grant meetings and events, Natasha expressed a profound appreciation for the work and a visible affinity and respect for 'TEGS' research team. As she explains:

\begin{abstract}
I'm really appreciative of your guy's program, TEGS, because I really feel like it's going to take an outside influence like an academic institution outside of the school board to ignite the fire that needs to be ignited in order to afford change, because we are weary and we don't have a lot of clout, but other institutions do. And, what you guys are doing is really making a difference. More and more people are feeling like there is a beacon of hope.
\end{abstract}

By regularly convening highly engaged teachers in meetings and professional development training sessions, the TEGS' Small Grants initiative alongside other TEGS activities, has given over 100 Vancouver educators fuel to ignite or sustain this fire of change.

\title{
Environmental Youth Alliance: Promoting Self-Sufficiency
}

This section describes the impact that the Small Grants initiative has had on one of the key community non-profit organizations working in the TEGS community of learners. During the first year of the Small Grants initiative Matthew Kemshaw worked with the Environmental Youth Alliance (EYA) to redesign the EYA's Growing Kids program. As the Program Coordinator from 2009-2012, Matthew collaboratively developed programming that would support school communities in building and maintaining outdoor food gardens as wholly integrated outdoor classrooms. Over the course of the Think\&EatGreen@School project, the EYA established relationships with 12 school communities, committing to working towards change in each community over a period of three years. As the Growing Kids coordinator, Matthew developed an internship program to train community members to co-facilitate a wide range of hands-on activities, which the EYA delivered regularly in its partner schools. In this time, the EYA also worked to convene school meetings and support educators in learning how to utilize school yard gardens as learning grounds.

The Think\&EatGreen@School Small Grants initiative helped the EYA to both expand and deepen its relationships with teachers and administrative staff in several schools. Working collaboratively with school communities to complete applications to the Small Grants initiative, 
Matthew witnessed these communities become more involved in school food system change. School community members began to see their work as situated within a larger, whole school food system. Once Small Grants were received, schools enjoyed a stronger atmosphere of support, and key champions began to see a growth of interest and curiosity towards their work from colleagues. As Matthew's successor at the EYA, Alaina Thebault explains, the process of writing the grant, receiving it, attending a large gathering of all TEGS schools, completing the projects funded by the grant, and then reporting on what they had accomplished, empowered schools to "build on what we're doing [as EYA program staff] and make it their own." The buy-in that the Small Grants Initiative engendered was a crucial tool in several schools, which helped the EYA to "deepen our work and create professional capacity within specific schools" (Alaina Thebault, personal communication). Synergistically, this was exactly the goal of the Growing Kids program, which hoped to be able to fade out its involvement within schools after three years and leave healthy school food gardens to be utilized and maintained by the school community.

One of EYA's biggest challenges was finding ways to support schools in becoming totally self-sufficient in the management of their school gardens. The experiences of the EYA supporting schools in writing Small Grants demonstrates how useful the initiative was in stimulating teacher interest and generating school activity towards the creation of healthier food systems. By pairing outside community support with a process for acquiring small grants, teachers gained access to both the knowledge and the tools to learn how to sustainably run integrated school food programs. By supporting this beneficial pairing, the Small Grants Initiative established school gardening as something worth valuing and investing in. Through the process of writing, receiving and reporting on their accomplishments, Matthew and Alaina both witnessed EYA's partner schools becoming much more invested in the success of their school food gardens. This is echoed in our report on Trafalgar Elementary in the 2013/14 school year, whose team stated that after working with EarthBites (another community nonprofit organization) to secure a Small Grant, "it started to be less like a 'field trip'... and began to be more embedded in the school culture."

\section{University Researcher - Generating Rich Data}

Elena Orrego is an anthropologist and co-founder of the Think\&EatGreen@School project. She is a member of TEGS Coordinating Committee and the Project Manager of TEGS. Elena has extensive national and international experience in community-engagement activities and scholarship. She has contributed from the beginning of the project to the ongoing dialogue on how to increase and secure the TEGS commitment to community engagement.

The Small Grants initiative gave TEGS' university-based researchers a level of immersion into the Vancouver school community that they otherwise would not have had. Developing entry into a community

[1] not necessarily guaranteed by carrying the university name or holding an advanced degree. Developing entry into the community organization involves getting to know 
the community of interest by spending time learning about the organization's culture, history in the community, and vision for the future. (Harper et al., 2004 as cited in Suarez-Balcazar et al., 2005, p.87).

Investing in school communities gave TEGS' research team critical access to the individual cultures, histories, and future visions of the school teams most impacted by the problems our research sought to address. This access, in turn, led to interactions within the communityuniversity alliance that may not have happened otherwise. Key players within the school communities were identified, challenges and capacities were established that were unique to each school team, and opportunities for community-engaged scholarship and further research were realized, in large part because the Small Grant initiative facilitated frequent visits to Small Grant schools and bi-annual meetings of school teams.

Information collected throughout the length of the Small Grants initiative included a range of qualitative and quantitative data that built on the histories of individual school partners as they reapplied for funding each year. With rich data collected via applications, self-assessment, and project poster reports, the Small Grants served as a tool for identifying challenges, needs, capacities, and opportunities that were distinct to each school's community or endemic to the larger Vancouver school context. Emergent patterns in this data have proven key to TEGS researchers, allowing us to 1) identify ways that the project can better support schools by connecting them with others working on similar projects or issues; 2) design resources, workshops, and events that can address challenges prevalent amongst many of the school communities, and; 3) work within the VSB to address policies that can better support school needs and capacities. The history that has also been established through working with some of the school partners since 2011 has given the TEGS team opportunities for comparison and analysis of how each school's circumstances have changed over the course of the project. In this way, TEGS has been able to not only better understand its influence in transforming school food systems in Vancouver, but also make decisions that better support the champions within the school system who are working so hard to create school food system change.

\section{Conclusion}

Although the Small Grants initiative was not initially included in the original TEGS research grant application submitted to SSHRCC, which only stated the intention of developing "Community Impacts Projects" to be elaborated with the school communities, it emerged as a key tool for conducting community-engaged scholarship and became an integral part of the overall TEGS Project. The Small Grants initiative demonstrated that TEGS explicitly valued the role of school community voices within the Project, contributed alongside other TEGS initiatives to create opportunities for resource and knowledge sharing, generated rich information and valuable data, supported and contributed to form critical networks of support and resource sharing, and sought to articulate the interests of a broad diversity of stakeholders. The willingness of TEGS to share resources through a small granting program also contributed to a leveling of the traditional power-dynamics often problematic in community-university 
research relationships. The multiplicity of connections and relationships created by the Small Grant Initiative situated university-based researchers in their environment of study, providing a deeper understanding of the individual contexts of each of the school communities, as well as the broader landscape that is the Vancouver school food system.

Through the sharing of funds our Small Grant initiative created multiple outcomes and useful indicators to measure the overall project's success. We feel that the care and time taken to build and foster relationships within our community-university alliance must not be overlooked in this accounting, nor should the challenges faced in the process be ignored. Regular gatherings and genuine social interactions were important for creating an environment of trust, mutual respect, and reciprocity; these convivial gatherings generated much knowledge and are in themselves useful indicators of our project's success. University researchers, university students, community-based non-profit organizations, and individual school teams all shared their unique experiences and knowledge. Supporting the connections between different stakeholders, legitimizing their experiences, and recognizing their efforts were all keys that unlocked many of the advances made by the TEGS Project. Building these relationships takes time and intention. Facilitating large group meetings and hosting multiple events every year was a significant undertaking. One key challenge in this process was finding the time and resources to properly support and encourage our community of learners. The TEGS research project invested heavily in this undertaking.

The investments made in supporting school actors and advancing action projects meant less resources and time were spent analyzing and communicating key academic learnings that emerged from all of our collected data. Many of the advances made by the TEGS project are not well documented in academic literature. A significant amount of the communication of our work and learnings has been done orally in dialogue with our large community of learners, as we read and engage with their work and learnings. Some of the work of analyzing all of our collected data and communicating the knowledge generated by it remains for future students and scholars interested in our questions and approach.

Although we are confident that some initial funding is a key component in supporting increased collaboration towards truly healthy school food systems, there is a possibility that the Small Grants initiative may have created some degree of dependency on small amounts of funding that originated from sources other than the schools themselves, or the VSB. While this may be the case, we also believe that funding from the Small Grants initiative has assisted in the creation of a strong community of teachers, community partners, parents, students, and university partners. Such connection within the school food network helps ensure that schools are resilient and able to find the future resources that will be needed to continue growing, eating, and composting food at the school level, and to give students the tools necessary to become literate in such critical skills.

There is also the question of equal distribution versus affirmative action, and whether the TEGS project should have supported fewer schools with larger funding amounts as opposed to a greater number of schools with smaller funding amounts. This is especially relevant in that significant challenges were often faced at an institutional level by the small grant teams 
and the Small Grants initiative. Obstacles related to the use of school space, and the increase of work that having gardens or compost systems implied for teachers and grounds staff, were often challenges for small grant teams wanting to implement sustainable food system projects. There could be some merit in providing fewer schools with larger amounts of funding and more organizational support in the hope that they become leading examples to the rest of the school community, effecting change at an institutional level so that effective policies and support networks are already in place when challenges arise. The process of allocating funding was very much run by the university researchers; we never developed an advisory committee made up of small grants holders to advise on how the program should run, and so never gathered more input from schools about the way the initiative was implemented. This would have been another way of sharing power and learning how best to support our community of learners.

Schools are agents of cultural and social change. The relationships and projects supported by the Small Grants Initiative will require continued support and encouragement if they are to flourish. By inviting school actors into our community-university alliance, school communities have become active agents in this research, rather than passive subjects. School efforts have been legitimized and rewarded. When teachers, students, and their larger communities become active citizens rather than remain passive, we find ourselves one step closer to the goal of school food system transformation. The Small Grants Initiative has helped make progress towards our goal of "learn[ing] to see food as the grand connector of all aspects of human life, including the relationships between humans and nature" (Rojas et al., 2011, p.3). Yet our progress is very much incomplete, and much work remains to be done. Our project has reached the end of its funding cycle and while important progress was made to embed the activities and goals of TEGS within the institutions involved, we are worried that without support, some of the projects we have supported will fail. We hope that support for individual school food action initiatives will continue to grow and evolve in the VSB for many years to come.

\section{Acknowledgements}

This research was supported by the Social Sciences and Humanities Research Council of Canada. We would like to thank Gwen Chapman and Jennifer Black for their careful feedback on earlier drafts. 


\section{About the Authors}

Matthew Kemshaw (corresponding author) holds a Master's degree in Environmental Education and Communications and a Bachelor's degree in Environmental Studies and Political Science. He works as a community organizer and environmental educator, with a primary focus on restoring ecological health to heavily urbanized environments. Email: matthewkemshaw@ gmail.com

Nicole Read holds a B.Sc. in Applied Biology from UBC. She has worked on a diverse range of projects related to urban farming and food security, pollinator health, and community development. She originally came to the Think\&EatGreen@School Project as a student and then later joined the team as a research assistant.

Alejandro Rojas is an Emeritus Professor at UBC's Faculty of Land and Food Systems and was one of the two founders of the Graduate Program in Integrated Studies in Land and Food Systems. He received the 2016 Canadian Award of Excellence in Food Studies and was the Principal Investigator of Think\&EatGreen@School.

Elena Orrego is originally from Chile and has lived in Canada for most of her adult life. She holds a Bachelor's Specialist and Master's degree in Anthropology from the University of Toronto in Canada. Elena has studied and worked in herbal medicine for many years.

\section{References}

Ahmadi, N., Black, J. L., Velazquez, C. E., Chapman, G. E., \& Veenstra, G. (2014, June 19). Associations between socio-economic status and school-day dietary intake in a sample of grade 5-8 students in Vancouver, Canada. Retrieved from https://open.library.ubc.ca

Balcazar, F., Keys, C., Kaplan, D., \& Suarez-Balcazar, Y. (1999). Participatory action research and people with disabilities: Principles and challenges. Canadian Journal of Rehabilitation, 12, 105112.

Belcher, B., Rasmussen, K., Kemshaw, M., Zornes, D. (2016). Defining and assessing research quality in a transdisciplinary context. Research Evaluation, 25(1), 1-17.

Black, J.L., Velazquez, C.E., Ahmadi, N., Chapman, G.E., Carten, S., Edward, J., Shulhan, S., Stephens, T. and Rojas, A. (2015). Sustainability and public health nutrition at school: Assessing the integration of healthy and environmentally sustainable food initiatives in Vancouver schools, Public Health Nutrition, 18(13), 2379-2391.

Carew, A. L., \& Wickson, F. (2010). The TD Wheel: A heuristic to shape, support and evaluate transdisciplinary research. Futures, 42(10), 1146-1155.

Engaged Scholar Journal: Community-Engaged Research, Teaching, and Learning 
Cash, D., et al. (2002). Decision making salience, credibility, legitimacy and boundaries: Linking research, assessment and decision making. KSG Faculty Research Working Paper Series. John F. Kennedy School of Government, Harvard University. November, 2002: RWPo2-046.

Chataway, J., Smith, J., \& Wield. D.(2007). Shaping scientific excellence in agricultural research. International Journal of Biotechnology, 9(2), 172-187.

Cloete, N. (1997). Quality: Conceptions, contestations and comments. African Regional Consultation Preparatory to the World Conference on Higher Education. 1-4 April 1997. Dakar, Senegal.

de Jong, S. P. L., van Arensbergen, P., Daemen, F., van der Meulen, B., \& van den Besselaar, P. (2011). Evaluation of research in context: an approach and two cases. Research Evaluation, 20(1), 6172.

Foster-Fishman, P. G., Berkowitz, S. L., Lounsbury, D. W., Jacobson, S., \& Allen, N. A. (2001). Building collaborative capacity in community coalitions: A review and integrative framework. American journal of community psychology, 29(2), 241-261.

Harper, G.W. \& Carver, L.J. (1999). "Out-of-the-mainstream" youth as partners in collaborative research: Exploring the benefits and challenges. Health Education \& Behavior, 26(2), 250-265.

Hemlin, S. (2006). The shift in academic quality control. Science, Technology \& Human Values, 31(2), 173-98.

Hemlin S. \& Rasmussen S.B. (2006). The shift in academic quality control. Science, Technology \& Human Values, 31(2), 173-198.

Israel, B.A., Schulz, A.J., Parker, E.A., \& Becker, A.B. (1998). Review of community-based research: Assessing partnership approaches to improve public health. Annual Review of Public Health, 19, 173-202.

Korzun, M., Alexander, C., Cluskey-Belanger, L.-J., Fudger, D., Needham, L., Vsetula, K.,Williamson, D., \& Gillis, D. (2014). The farm to fork project: Community-engaged scholarship from community partners' perspective. Gateways: International Journal of Community Research and Engagement, 7, 101-115.

Mattessich, P. W., \& Monsey, B. R. (1992). Collaboration: what makes it work. A review of research literature on factors influencing successful collaboration. Amherst H. Wilder Foundation, 919 Lafond, St. Paul, MN 55104.

Nyden, P., Maly, M., \& Lukehart, J. (1997). The emergence of stable racially and ethnically diverse urban communities: A case study of nine US cities. Housing Policy Debate, 8(2), 491-534.

Ozga, J. (2007). Co-production of quality in the Applied Education Research Scheme. Research Papers in Education, 22(2), 169-181.

Rojas, A., Valley, W., Mansfield, B., Orrego, E., Chapman, G.E., \&Harlap, Y. (2011). Toward food system sustainability through school food system change: Think\&EatGreen@School and the making of a community-university research alliance. Sustainability, 3, 763-788.

Selener, D. (1997). Participatory action research and social change. Ithaca, New York: Cornell University.

Spaapen, J., Dijstelbloem, H., \& Wamelink, F. (2007). Evaluating research in context: A method for comprehensive assessment. Netherlands: Consultative Committee of Sector Councils for Research and Development. Retrieved from http://www.qs.univie.ac.at/fileadmin/user_ upload/qualitaetssicherung/PDF/Weitere_Aktivit\%C3\%A4ten/Eric.pdf

Suarez-Balcazar, Y., Harper, G.W., \& Lewis, R. (2005). An interactive and contextual model of community university collaborations for research and action. Health Education $\approx$ Behaviour, 32(1), 84-101. 